\title{
Long-term sea level change in the Malaysian seas from multi-mission altimetry data
}

\author{
Ami Hassan Md Din ${ }^{1 *}$, Kamaludin Mohd Omar ${ }^{1}$, Marc Naeije $^{2}$ and Sahrum Ses ${ }^{1}$ \\ ${ }^{1}$ GNSS and Geodynamics Research Group, Infocomm Research Alliance, Faculty of Geoinformation and Real Estate, \\ Universiti Teknologi Malaysia, 81310 Skudai, Johor, Malaysia. \\ ${ }^{2}$ Faculty of Aerospace Engineering, Delft University of Technology, Kluyverweg 1, 2629 HS Delft, The Netherlands.
}

Accepted 09 February, 2012

\begin{abstract}
The long-term sea level change during 1993 to 2008 was investigated in the Malaysian seas from satellite altimetry data of the TOPEX, JASON-1, ERS-1, ERS-2 and ENVISAT missions. Sea level data retrieval and reduction were carried out using the radar altimeter database system (RADS). In RADS data processing, the 2008 updated environmental and geophysical corrections were applied. Six $1^{\circ} \times 1^{\circ}$ areas were chosen for the altimetry data comparison and to find the best ocean tide model for the Malaysian seas, where the altimeter tracks are nearby tide gauge locations. Similarity in the patterns of sea level variations indicates good agreement between tide gauge and altimetry data when using the FES2004 ocean tide model. It also shows that altimetry data is perfectly suited to investigate long-term sea level change in the Malaysian seas. Here, sea level variations for four areas in the Malaysian seas have been investigated using 15 years of altimetry data. The altimeter sea level time series revealed that since 1993, the mean sea level in Malaysian seas has been rising at a geographically-dependent rate varying from 1.4 to $4.1 \mathrm{~mm} / \mathrm{yr}$. This kind of information is important for studying environmental issues related to flood investigations and global warming especially for an area that until now have not gotten much attention from the altimeter science community.
\end{abstract}

Key words: Sea level change, multi-mission altimetry, ocean tides, tide gauges.

\section{INTRODUCTION}

Long-term sea level change is important for a variety of environmental and socio-economic reasons, especially for the large portion of the world's population living in the coastal zone. Changes in sea level have traditionally been measured at a number of fixed tide gauge stations around the globe, but with the increased accuracy of satellite altimetry, this now offers the best opportunity for improving our knowledge on global and regional sea level change (Fu and Cazenave, 2001).

The primary source of information on sea level change over the past century are tide gauge measurements. However, tide gauges poorly sample the global oceans

*Corresponding author. E-mail: amihassanmddin@gmail.com. Tel: +60137975476 . Fax: +6075530536 . and can also be affected by vertical land motions unrelated to climate-driven sea level variations. Instead, satellite measurements over the last decade have revolutionized our understanding of sea level change (Nerem et al., 2006).

Satellite altimetry is the space observing technique for the oceans. Observations from satellite altimeters during the past two decades have provided dramatic descriptions of sea level variability with higher spatial resolution than tide gauges. Long-term changes in sea level may be due to phenomena such as deformation of the ocean basin or land uplift/subsidence. Another important parameter is the melting of ice caps and thermal expansion/contraction of the oceans.

According to Nerem and Mitchum (2001), it is confirmed that globally the sea level has risen during the 20th century and it is still going on. The main driver is 
global temperature change (global warming phenomenon). There are several possible negative impacts of sea level rise to coastal environment in the future such as beach erosion, inundation of land, increased flood and storm damage, increased salinity of coastal aquifers and coastal ecosystem loss. Therefore, an understanding of past and future changes in sea level and related ocean are important in coastal management.

In Naeije et al. (2008), almost 17 years sea level change was studied combining all available altimeter (leaving out GEOSAT and POSEIDON). The study came out with the analysis of the global mean sea level rise at the rate of $2.53 \mathrm{~mm} /$ year. In addition, Omar et al. (2006) shows that over the past few decades, satellite altimetry demonstrated its capability in measuring temporal change of the global mean sea level with a precision around $2 \mathrm{~cm}$ and the sea level trends can be resolved better than 1 $\mathrm{mm} / \mathrm{yr}$. Sea level rise was estimated ranging from 1.5 to $8.9 \mathrm{~mm} /$ year using two decades of tide gauges observations along the coast of Malaysia. Comparison of $1^{\circ} \times 1^{\circ}$ areas at the tide gauge locations nearby Topex track clearly showed good agreement in pattern and trend of sea level variations.

During the past centuries, coastal tide gauges have provided the main technique to measure sea level change for Malaysian seas. However, there are two main problems faced in monitoring regional sea level changes by using tide gauges in the region: only few stations provide long enough records, and the geographical distribution is uneven because the stations are usually installed in the coastal area and there are no long term records from the deep ocean.

An alternative to overcome these problems is to measure the sea level from space, that is, by means of the satellite altimetry technique. Altimetry provides good potential as a complementary tool to the traditional coastal tide gauge instruments in monitoring sea level change in Malaysian seas. In addition, there have not been much altimeter studies in our region. This research is the first systematic investigation on the sea level rise phenomena in Malaysian seas, based on a relatively long record ( 15 years) of satellite altimetry data.

\section{MULTI-MISSION ALTIMETER AND DATA PROCESSING}

Satellite altimeter measurements have now been continuously available since 1991, through the ERS-1, TOPEX/Poseidon, ERS-2, Geosat Follow-on, JASON-1 and ENVISAT missions. Measurements from these instruments have revolutionized our knowledge of the ocean, through studies in sea level, ocean circulation and climate variability.

In 1992, the TOPEX/Poseidon altimetry satellite was launched and its mission endured to October 2005. Since
2002, its original ground track was overtaken by its successor JASON-1. Both satellite missions provide the most precise altimetry data when compared to others, mainly due to the very precise orbit determination. The ground track pattern of these satellites repeats every 10 days, providing near-global (within $\pm 66^{\circ}$ latitude) maps of sea level change with this temporal sampling (Nerem et al., 2006). Although, satellite altimetry records are still quite short compared to the tide gauge data sets, this technique appears quite promising for the sea level change issue because it provides sea level measurement with very good spatial coverage (Cecile et al., 2001).

Meanwhile, the European Space Agency (ESA) launched the ERS satellites (1 and 2 in 1991 and 1995 respectively). These satellites were the first missions acquiring commercially available microwave radar data, offering new opportunities for all-weather remote sensing applications. Both were launched into a sun-synchronous orbit at an inclination of $98^{\circ}$ and an altitude between 782 and $785 \mathrm{~km}$, making them less suitable for ocean tide studies and more susceptible to atmospheric drag resulting in slightly less orbit accuracy. In March 2002, ESA launched the Environmental Satellite (ENVISAT), an advanced polar-orbiting earth observation satellite that provides measurements of the atmosphere, ocean, land and ice. This satellite mission is the successor to the ERS satellites, and is still operational (Dumont et al., 2006).

Generally, radar altimetry is among the simplest of remote sensing techniques. Two basic geometric measurements are involved in this technique. Firstly, the distance between the satellite and the sea surface is determined from the round-trip travel time of microwave pulses emitted downward by the satellite's radar, reflected back from the ocean, and received again on board. Secondly, independent tracking systems are used to compute the satellite's three-dimensional position relative to a fixed earth coordinate system. Then, combining these two measurements yields profiles of sea surface topography, or sea level, with respect to the reference ellipsoid (a smooth geometric surface which approximates the shape of the Earth) (Fu and Cazenave, 2001). Figure 1 shows the satellite altimetry measurement principle.

In this study, sea level data retrieval and reduction were carried out using the RADS, the archiving and processing initiative of TUDelft, NOAA and Altimetrics LLC (Naeije et al., 2008). This system was installed in Malaysia at Universiti Teknologi Malaysia (UTM) in 2005 in the frame of the SEAMERGES project, an EU funded project (AUNP) that aimed for knowledge, methods and data exchange related to satellite altimetry, InSAR and GPS (www.deos.tudelft.nl/seamerges). In RADS data processing, the 2008 updated environmental and geophysical corrections were applied. The sea level data have been corrected for orbital altitude; altimeter range 


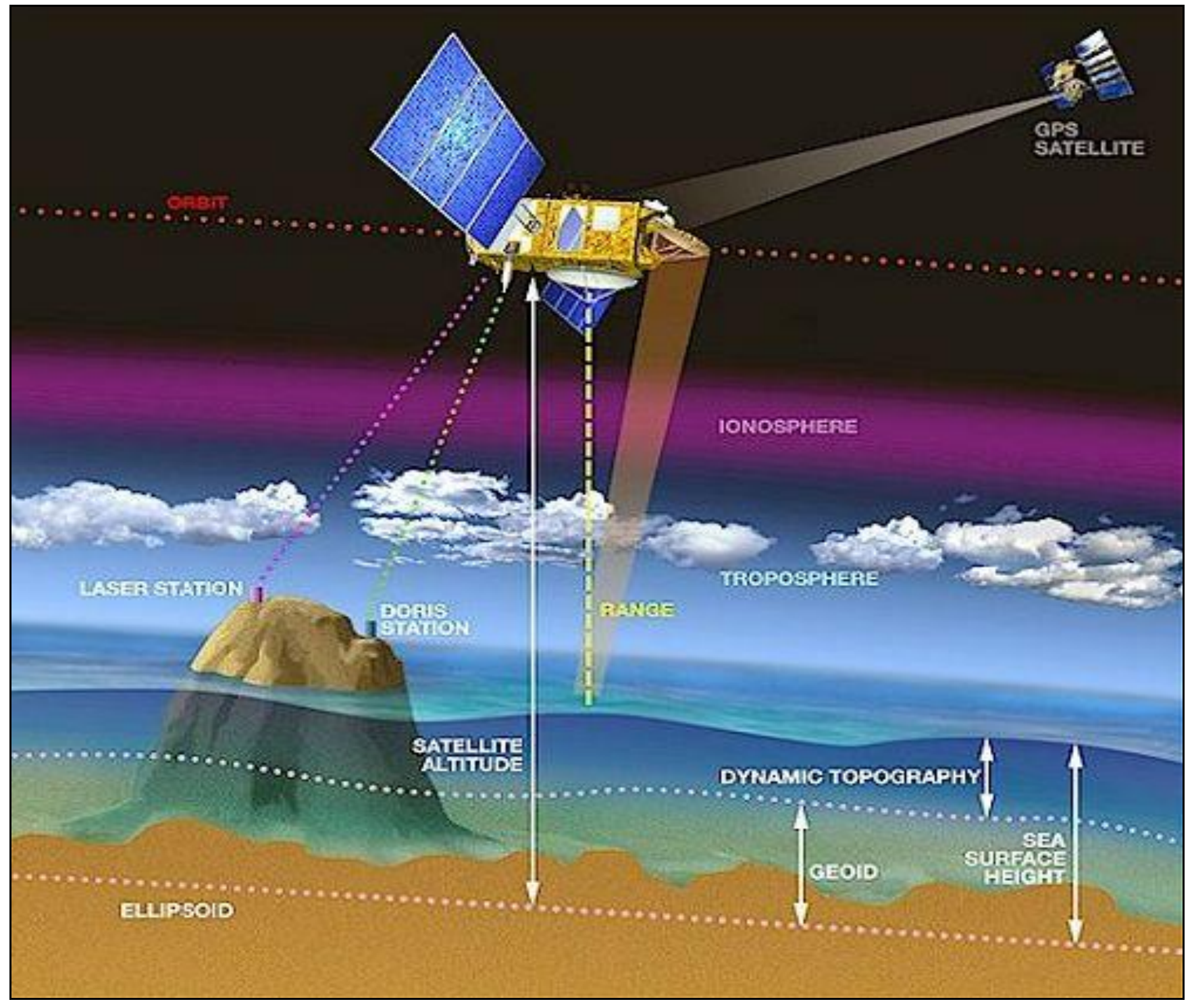

Figure 1. Principle of satellite altimeter (courtesy of AVISO).

corrected for instrument, sea state bias, ionospheric delay, dry and wet tropospheric corrections, solid earth and ocean tides, ocean tide loading, pole tide, electromagnetic bias and a dynamic atmosphere correction. The corrections were done by applying specific models for each satellite altimetry missions in RADS. These corrections are summarized in Table 1.

Furthermore, due to factors such as orbit error and inconsistency in the satellite orbit frame, the sea surface heights (SSH) from different satellite missions need to be adjusted to a 'standard' surface. In this research, the SSH from the Topex mission have served as a standard surface in the stage of processing integrated data because of its highly accurate orbit. This is called cross- over adjustment for multi-satellite missions (Huang et al., 2008).

\section{Local mean sea level (MSL) observed by tide gauges}

In Malaysia, there are 12 tidal stations along the coast of Peninsular Malaysia (West Malaysia) and 9 tidal stations along the coast of Sabah and Sarawak (East Malaysia). Figure 2 shows the location of tidal stations in Malaysia. This tidal network has been operational since 1984 along the coastal areas of Malaysia. The main objective of this continuous observation network is to enable continuous time series of sea level heights to be obtained for the purpose of establishing a unified vertical datum for 
Table 1. Corrections and models applied for sea level data extraction in RADS.

\begin{tabular}{|c|c|c|c|}
\hline \multirow{2}{*}{ Correction/Model } & \multicolumn{2}{|c|}{ Editing $(m)$} & \multirow[t]{2}{*}{ Description } \\
\hline & Min & Max & \\
\hline Orbit/ Gravity field & & & $\begin{array}{l}\text { TOPEX: GGM02C, } \\
\text { JASON-1 \& ENVISAT: EIGEN CG03C, ERS: DGM-E04 }\end{array}$ \\
\hline Dry troposphere & -2.4 & -2.1 & All satellites: ECMWF \\
\hline Wet troposphere & -0.6 & 0.0 & All satellites: Radiometer measurement \\
\hline lonosphere & -0.4 & 0.04 & $\begin{array}{l}\text { All satellites: Smoothed dual-freq, } \\
\text { ERS: NIC08 }\end{array}$ \\
\hline Dynamic atmosphere & -1.0 & 1.0 & All satellites: MOG2D \\
\hline Ocean tide & -5.0 & 5.0 & All satellites: FES2004 / GOT00.2 / No ocean tide \\
\hline Load tide & -0.5 & 0.5 & All satellites: FES2004 / GOT00.2 / No load tide \\
\hline Solid earth tide & -1.0 & 1.0 & Applied (Elastic response to tidal potential) \\
\hline Pole tide & -0.1 & 0.1 & Applied (Tide produced by Polar Wobble) \\
\hline Sea state bias & -1.0 & 1.0 & $\begin{array}{l}\text { All satellites: CLS non parametric } \\
\text { ERS: BM3/BM4 parametric }\end{array}$ \\
\hline Reference & -1.0 & 1.0 & CLS01 mean sea surface \\
\hline Engineering flag & & & Applied \\
\hline Applied reference frame biases $(\mathrm{cm})$ & & & $\begin{array}{l}\text { JASON-1: -2.1, ERS-1: -2.3, } \\
\text { ERS-2: -4.1, ENVISAT: -3.2 } \\
\text { TOPEX: Reference frame }\end{array}$ \\
\hline
\end{tabular}
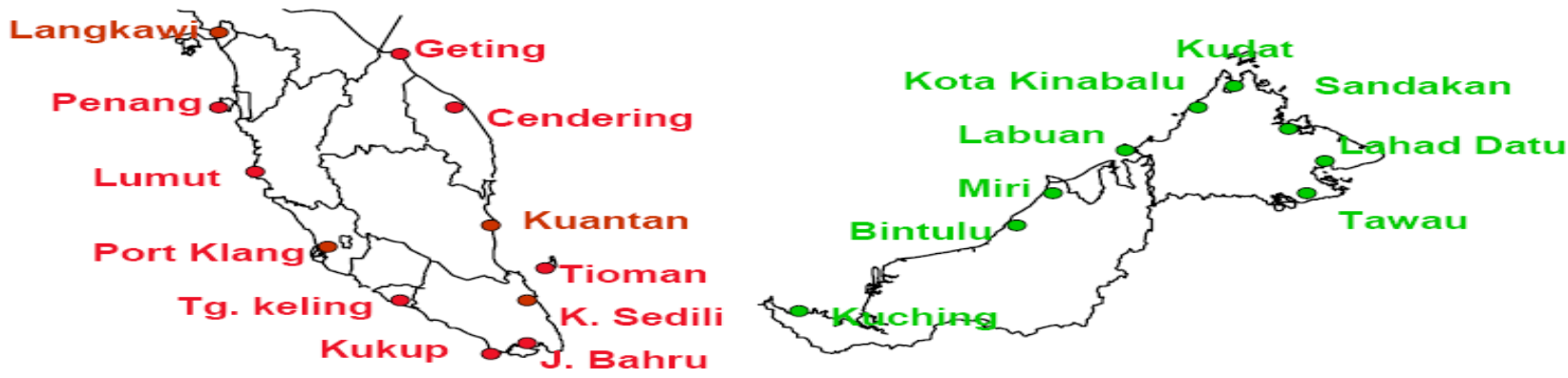

Figure 2. Location of tidal stations in Malaysia.

Malaysia. Appendix Figure A1 show the plots of monthly mean sea levels for tide gauge stations in the West Coast of Peninsular Malaysia (a), in the East Coast of Peninsular Malaysia (b), and in Sabah and Sarawak (c).

From the curves in Figure A1, we determine the trends over the 15-year period (1993 to 2008) using linear regression analysis. The trends for tide gauge stations in Malaysia are given in Table 2. In this study, an annual cycle has been removed to find the sea level trend at the tide gauge stations. The tidal data has been filtered by monthly averaging. However, the tidal data has not been corrected for GIA and other land motion like tectonics, subsidence, etc. The result shows that trends do exist in the sea level height around Malaysia and vary quite significantly from one location to the other. Furthermore, the linear trends of the mean sea level (MSL) variations are positive, indicating an overall rise in the sea level around the coast of Malaysia.

The rise ranges from $1.2 \mathrm{~mm} / \mathrm{yr}$ at $\mathrm{P}$. Langkawi to 3.0 $\mathrm{mm} / \mathrm{yr}$ at Kukup on the west coast of peninsular. Taking the average of the west coast of the peninsular group, it shows that the relative sea level trend is about $2.0 \mathrm{~mm} / \mathrm{yr}$. Meanwhile, for the east coast of peninsula, the rise ranges from $1.7 \mathrm{~mm} / \mathrm{yr}$ at Geting to $3.2 \mathrm{~mm} / \mathrm{yr}$ at Chendering. The average of sea level trends at east coast of peninsular is therefore approximately $2.4 \mathrm{~mm} / \mathrm{yr}$. 
Table 2. Sea level change in the Malaysian waters from tide gauge station (1993 to 2008).

\begin{tabular}{llc}
\hline Location of tide gauge & Tide gauge stations & Linear trend $(\mathbf{m m} / \mathbf{y r})$ \\
\hline & P. Langkawi & 1.2 \\
& P. Pinang & 1.8 \\
West Coast Peninsular & Lumut & 2.3 \\
& Port Klang & 2.3 \\
& Tg. Keling & 1.4 \\
& Kukup & 3.0 \\
& Johor Bahru & 2.2 \\
& Tg. Sedili & 1.8 \\
East Coast Peninsular & P. Tioman & 2.4 \\
& Tg. Gelang & 2.6 \\
& Chendering & 3.2 \\
& Geting & 1.7 \\
& Bintulu & 0.1 \\
& K. Kinabalu & 2.4 \\
Sabah and Sarawak & Sandakan & 3.5 \\
& Lahad Datu* & 0.2 \\
& Tawau & 2.8 \\
& Kudat & 0.6 \\
& Labuan & 0.9 \\
\hline
\end{tabular}

*Data from 1996 to 2008.

In Sabah and Sarawak, the rate of sea level was calculated without including Lahad Datu, Kudat and Labuan stations. The rates of those locations are likely to be incorrect because the data is not continuous and the period is too short. The rise in this group ranges from $0.1 \mathrm{~mm} / \mathrm{yr}$ at Bintulu to $3.5 \mathrm{~mm} / \mathrm{yr}$ at Sandakan. The average of the sea level trend in this group is estimated at $2.2 \mathrm{~mm} / \mathrm{yr}$. Taking the combination of the sea level trend of the three groups, it shows an average trend for the Malaysian seas of about $2.2 \mathrm{~mm} / \mathrm{yr}$ solely based on tide gauges data, which is close to the generally accepted global average value of $1.8 \mathrm{~mm} / \mathrm{yr}$ over the last 5 decades.

\section{Altimeter sea level using different ocean tide models}

The oceanic tide is a periodic phenomenon of rise and fall of the sea level. It is governed by the gravitational attraction of the solar system bodies essentially the moon and the sun, translated to a transport of water masses. Each day, the sea rises and falls along the coasts around the world oceans with amplitudes that can reach several meters. In the past decade, with the advent of satellite altimeters that had routinely measured the sea surface level with an accuracy of a few centimeters, the accuracy of ocean tide modelling greatly improved. The use of altimeter measurements in ocean tide models has some problems, caused by the sampling frequency and the spatial sparseness of the data. But these problems have been overcome with the help of advanced processing techniques and data assimilation methods. In this research, the evaluation of the ocean tide model was calculated using two global models GOT00.2 and FES2004.

The ocean tide model GOT00.2 (Goddard Ocean Tide) is essentially an update of GOT99.2 ocean tide model. Solution GOT00.2 used 286 cycles of TOPEX and Poseidon data, supplemented in shallow seas and in polar seas (latitudes above 66 degrees) by 81 cycles of ERS-1 and ERS-2 data. The solution consists of independent near-global estimates of 7 constituents (Q1, O1, K1, N2, M2, S2, K2, with P1 inferred) (Ray, 1999).

Meanwhile, FES2004 ocean tide model is based on the resolution of the tidal barotropic equations on a new global finite element grid ( $\sim 1$ million nodes), which leads to solutions independent of in situ and remote-sensing data. A new original high-resolution bathymetry is used and the ice on Polar Regions is taken into account. The accuracy of these 'free' solutions is improved by assimilating tide gauge and altimetry data (T/P and ERS2 ) through a revised represented assimilation method ( $F$. Lyard et. al., 2006).

In addition, FES2004 model is a dynamic model with 
Table 3. Altimeter sea level trends using different ocean tide options (1993 to 2008).

\begin{tabular}{lccc}
\hline Location & FES2004 (mm/yr) & GOT00.2 (mm/yr) & No model $(\mathbf{m m} / \mathbf{y r})$ \\
\hline K. Kinabalu & 2.7 & 2.7 & 3.3 \\
Tawau & 2.8 & 3.3 & 4.3 \\
Sandakan & 3.3 & 2.3 & 3.0 \\
Geting & 1.9 & 2.4 & 2.0 \\
P. Tioman & 2.4 & 4.0 & 1.3 \\
P. Langkawi & 1.5 & 1.9 & 6.5 \\
\hline
\end{tabular}

assimilation from observed tidal data (altimeter and coastal and pelagic tide gauges). Besides, 15 tidal constituents are distributed on $1 / 8^{\circ}$ grids (amplitude and phase). Twenty-eight other constituents are taken into account by the means of a specific admittance method and a long period wave computation. A new prediction algorithm is distributed within the FES2004 package to provide tidal heights at any location of the world ocean.

In order to find the most suited global ocean tide solution for the Malaysian seas, satellite altimetry was processed by using 3 different ocean tide options (GOT00.2, FES2004, or no ocean tide correction). Six areas were chosen near the tide gauge stations. This is shown in Appendix Figure A2. The combination of TOPEX and JASON-1 satellites was used to extract precise sea level data from RADS. These satellites were chosen because they give more accurate data compared with the other altimeter satellites. Table 3 shows the result of the sea level trend for TOPEX and JASON-1 data extraction using the different ocean tide options for the selected $1^{\circ}$ by $1^{\circ}$ bin areas.

Like with the tide gauges, Table 3 shows that all the linear trends of the sea level variations using different ocean tide models are all positive, indicating again that overall sea level for the Malaysian Seas is rising. The rise ranges from $1.5 \mathrm{~mm} / \mathrm{yr}$ at $\mathrm{P}$. Langkawi to $3.3 \mathrm{~mm} / \mathrm{yr}$ at Sandakan, applying the FES2004 ocean tide model, whereas, the GOT00.2 ocean tide results show sea level trends ranging from $1.9 \mathrm{~mm} / \mathrm{yr}$ at $\mathrm{P}$. Langkawi to 4.0 $\mathrm{mm} / \mathrm{yr}$ at $\mathrm{P}$. Tioman. The results from the option using no ocean tide model are much worse (too far off from the two other cases), perfectly showing that you need an ocean tide model for sea level trend estimation from altimetry. This is mainly true due to tidal constituents' aliasing at lower frequencies (under-sampling) that are not averaged out when for instance calculating monthly means, whereas tide gauge data does not have this limitation (over-sampling).

\section{Comparison between altimetry and tidal data}

Here, we discusses in a bit more detail the comparison of satellite altimetry data with different ocean tide models applied and tide gauge data. We try to find the best general ocean tide model for the Malaysian seas. The comparison also validates the results from the combination of TOPEX and JASON-1. We look at the six $1^{\circ}$ by $1^{\circ}$ bin areas close to the tide gauge stations (Appendix Figure A2). We summarized the results of the comparison in Appendix Figures A3, A4 and A5.

As we already saw previously and now in these figures, the variation of sea level obtained from altimetry using different ocean tide models and tide gauges in $\mathrm{K}$. Kinabalu, Tawau, Sandakan, Geting, P. Tioman and P. Langkawi show similar patterns. It indicates the very good agreement between tide gauge data and altimetry data with both FES2004 and GOT00.2 tide models applied. We dismissed the "no tide model" case due to the nonusable result, as mentioned and explained before.

Linear trends of the combination of TOPEX/JASON-1 altimeter and tide gauge measurements were evaluated over the same period at each area in order to produce results that can be compared. Referring to Appendix Table A1, the comparison shows that the differences of linear trend between tide gauge and "altimetry FES2004 case" are quite small, within -0.3 to $0.1 \mathrm{~mm} / \mathrm{yr}$, whereas the differences of the sea level trend between tide gauge and "altimetry GOT00.2 case" show larger differences, ranging from -0.7 to $1.1 \mathrm{~mm} / \mathrm{yr}$. For completeness sake, we included in Table A1 the "altimetry no tide model case", which again is way off compared to the "tide included" cases.

These results basically encourage us to estimate the rate of sea level rise in Malaysian seas using the FES2004 ocean tide correction. It also shows that the altimetry data is fit to investigate sea level rise for Malaysian seas due to the small differences of linear trend between altimetry and tidal data, within -0.3 to 0.1 $\mathrm{mm} / \mathrm{yr}$. The overview of results is shown in Figure 3.

\section{Sea level trend using multi-mission altimetry}

As mentioned previously, it is well known that satellite altimeter is able to provide sea level observations with higher spatial resolution than tide gauges. We now use 5 altimeter missions to continue this study. Table 4 shows the summary of data that has been used. Altimetry data 


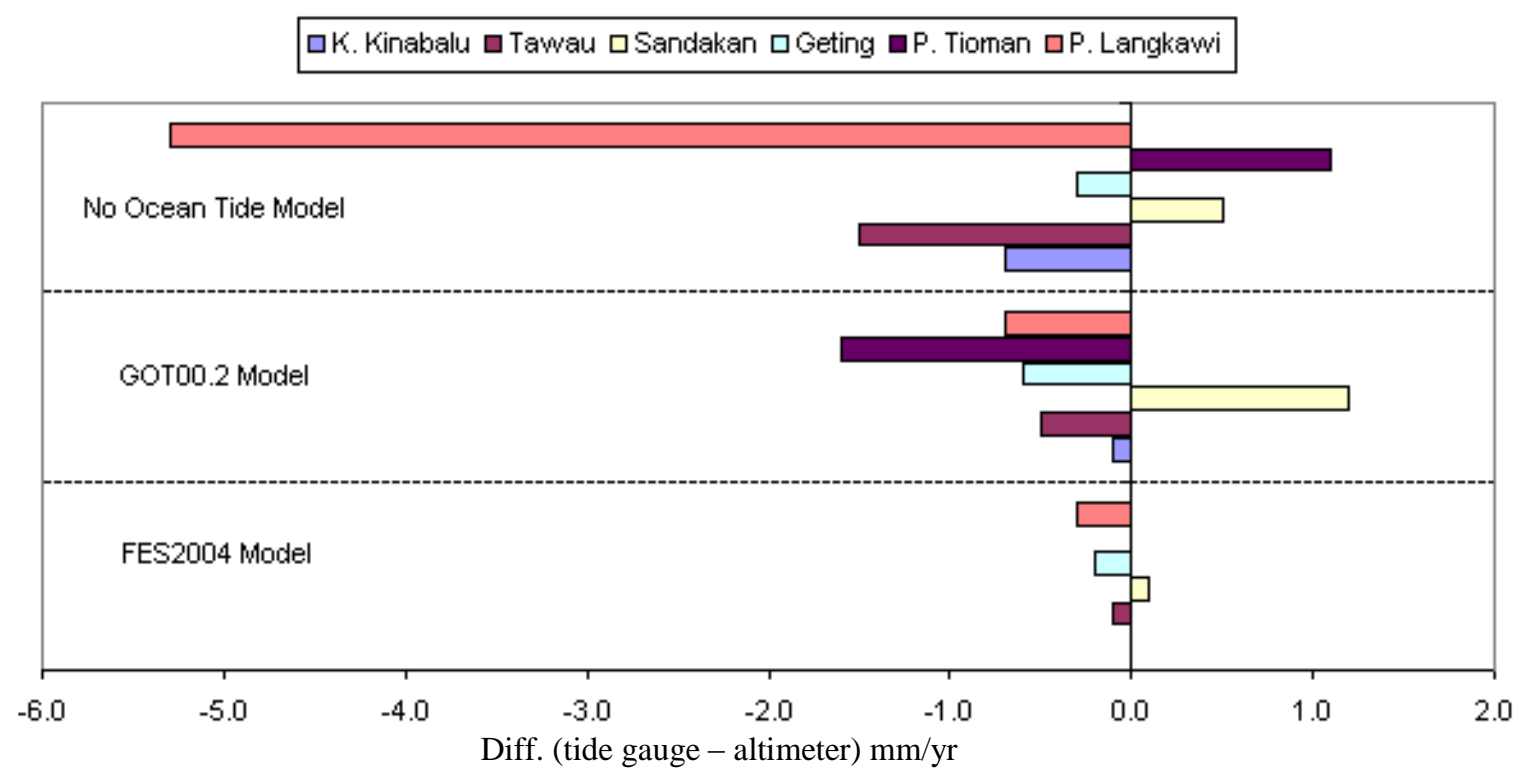

Figure 3. Sea level change differences between the tidal and altimetry results.

Table 4. Summary of altimeter data used.

\begin{tabular}{lllc}
\hline Satellite & Source & Period & Cycles \\
\hline TOPEX & NASA/CNES & Jan 1993 to July 2002 & 11 to 363 \\
JASON-1 & NASA/CNES & Aug 2002 to Apr 2008 & 21 to 230 \\
ERS-1 & ESA & Jan 1993 to Apr 1995 & 91 to 145 \\
ERS-2 & ESA & May 1995 to Sep 2002 & 01 to 78 \\
ENVISAT & ESA & Oct 2002 to Apr 2008 & 10 to 67 \\
\hline
\end{tabular}

was extracted ranging between $0^{\circ} \mathrm{N} \leq$ Latitude $\geq 15^{\circ} \mathrm{N}$ and $95^{\circ} \mathrm{E} \leq$ Longitude $\geq 125^{\circ} \mathrm{E}$, covering the Malaysian seas.

For the purpose of performing sea level change analysis on collinear track basis, these satellites missions were divided into two ground track cases. The first ground track case is the combination of TOPEX and JASON-1 (10-day repeat orbit). The other ground track case is the combination of ERS-1, ERS-2 and ENVISAT (35 day repeat orbit, 17-day sub-cycle). For each of the satellite missions the average over each cycle and over the entire Malaysian seas of the corrected SSH above mean sea surface model CLS01 (Collecte Localisation Satellites, France) was computed and a simple regression model (same as before) was fitted to the results. The regression model was performed to develop the sea level trend using altimetry data. Before developing the regression model, annual signal / relative offsets have been removed from the altimetry data and the dataset has also been filtered by one-month running means.

Four study areas were selected to investigate the sea level variation of the Malaysian seas: the South China Sea, the Malacca Strait, the Sulu Sea and the Celebes Sea (Appendix Figure A6). The FES2004 ocean tide model was employed in the process of data reduction. The time series of mean sea level were derived from the averages of monthly altimetry data.

The sea level time series of the South China Sea and the Malacca Strait using multi-mission altimetry are presented in Appendix Figures A7 and A8 respectively. Both depict that the rise of mean sea level is clearly visible in the altimetry data. The rate of sea level rise obtained from TOPEX/JASON-1 in South China Sea is about $2.0 \mathrm{~mm} / \mathrm{yr}$. Sea level trend of South China Sea from the combination of ERS-1, ERS-2 and ENVISAT was estimated at a different rate of $1.3 \mathrm{~mm} / \mathrm{yr}$. It is stressed that the two ground track cases indeed represent different sampling locations and therefore they belong to different parts of the ocean. With the combined observation of the five satellites, the estimated rate of the sea level time series of the South China Sea was about $1.6 \mathrm{~mm} / \mathrm{yr}$. Figure A7 also shows a clear short-term periodic circu- 
lation (annual cycle) with a slight longer term modulation compatible with the solar cycle.

Meanwhile, Appendix Figure A8 summarizes the results of mean sea level variation computations for the Malacca Strait using again the multi-mission altimetry data. For both ground track cases the linear regression shows a rise of $1.4 \mathrm{~mm} / \mathrm{yr}$, which also results in an average of 1.4 $\mathrm{mm} / \mathrm{yr}$ for all satellites combined. However, Figure A8 also shows that either the tide model applied is not very well suited for the Malacca Strait or there are other short term circulation dynamics that do not average out over this area, because the mean sea level evolution has a somewhat disturbed annual cycle with lots of higher harmonics. We believe this must be due to the fact that the Malacca Strait is shallow and rather narrow.

In addition, mean sea level variations for the Sulu Sea and the Celebes Sea are presented in Appendix Figures A9 and A10. Both figures show a similar pattern of sea level variations with a more or less regular annual cycle indicating that the chosen tide model is well suited for these areas. The effect of the 1997 to 1998 Los Niños on sea level is clearly visible: sea level drops below normal values late 1997 (El Niño), goes back to normal mid 1998, and overshoots a little at the end of 1998 (La Niña). Noticeable also is the overall larger sea level rise in these areas than in the previous two areas. Figure A9 shows for the Sulu Sea rates of 3.9, 3.6, and $3.8 \mathrm{~mm} / \mathrm{yr}$ respectively for the TOPEX/JASON-1, the ERS-1/ERS-2/ENVISAT, and the all-combined case. Similar values for the Celebes Sea can be found in Figure A10, resulting in an average of $4.1 \mathrm{~mm} / \mathrm{yr}$. Here, the annual cycle is less pronounced as opposed to the El Niño signal, which is very much present. A more precise estimate of the sea level trend should therefore include proper modeling of this phenomenon in order to remove it from the altimetry data record.

\section{DISCUSSION}

The merging of multi-mission altimetry data increases the time series lengths and the spatial and temporal resolution of the data. This advantage is important for long-term sea level change study, as the lifetime of a single altimeter satellite is too short for long term, decadal and inter-annual studies. In this study, altimetry data from different missions have been used over the same time span (15 years) to investigate sea level rise for the Malaysian seas. Analysis of the trends for tide gauge stations in Malaysia all show positive values, indicating an overall rise in the sea level around the coast of Malaysia. We established that sea level has been rising at a rate of 0.1 to $3.5 \mathrm{~mm} / \mathrm{yr}$ at tide gauge stations.

Subsequently, six $1^{\circ}$ by $1^{\circ}$ bin areas were chosen for the altimetry data validation and to find the best global ocean tide model suited for Malaysian seas, where altimeter tracks were investigated nearby the tide gauge locations. The linear trend for TOPEX/JASON-1 altimetry and tidal data were evaluated over the same period at each area in order to produce results that can be compared directly. Similarity on the patterns of sea level variations indicate good agreements between tidal and altimetry data when the FES2004 ocean tide model was applied. The differences of linear trend between tidal and altimetry data (FES2004 model) are small, within -0.3 to $+0.1 \mathrm{~mm} / \mathrm{yr}$, representing a realistic error bar for the trend determination. Thus, these results basically encouraged us to estimate the rate of sea level rise from all available altimetry data in the Malaysian seas using the FES2004 ocean tide model (as opposed to the GOT00.2 model).

Both the South China Sea and the Malacca Strait depicted that the rise of mean sea level was clearly visible from altimetry. The rate of sea level rise obtained with five satellites combined was about 1.6 and $1.4 \mathrm{~mm} / \mathrm{yr}$ respectively. Based on the result, the short-term periodic (annual) circulation of mean sea level was revealed at the open South China Sea. However, the applied tide model did not fit well in the shallow Malacca Strait, where the short-term ocean circulation appeared to be disturbed by higher harmonics ("noisy"). This must be due to the fact that the Malacca Strait is narrow and shallow. Meanwhile, mean sea level variations for Sulu Sea and Celebes Sea show that both areas have a similar pattern of sea level variations and the tide model seems suited for both areas. The effect of Los Niños on the sea level was clearly visible when the sea level began to fall abnormally, late 1997 and reverted to normal after 1998. The increase of the sea level trend in both these areas, 3.8 and 4.1 $\mathrm{mm} / \mathrm{yr}$ respectively, was significantly higher than those for the South China Sea and the Sulu Sea. However, one has to bear in mind that the Los Niños signals would likely have affected the linear regression, even though they occurred only once within the time span of our investigation.

Having enough confidence in the data and choosing the methods for processing all the data together, we can claim that since 1993 until 2008, the mean sea level in Malaysian seas has been rising at a rate of 1.4 to 4.1 $\mathrm{mm} / \mathrm{yr}$ for the chosen sub-areas, with an overall mean of $2.8 \mathrm{~mm} / \mathrm{yr}$. This kind of information on water level rise is important to study environmental issues related to flood investigations, global warming and perhaps alternative energy extraction.

Nonetheless, we believe that to discover the actual rate of sea level rise in this region, we need at least 18.6 years of data to be able to correct for the lunar nutation effect (Loder and Garret, 1978). Not correcting the lunar nodal tide effect can impact the trend estimate for a period much shorter than 18.6 years. This uncorrected contribution can be noticed in both the altimetry and tidal 


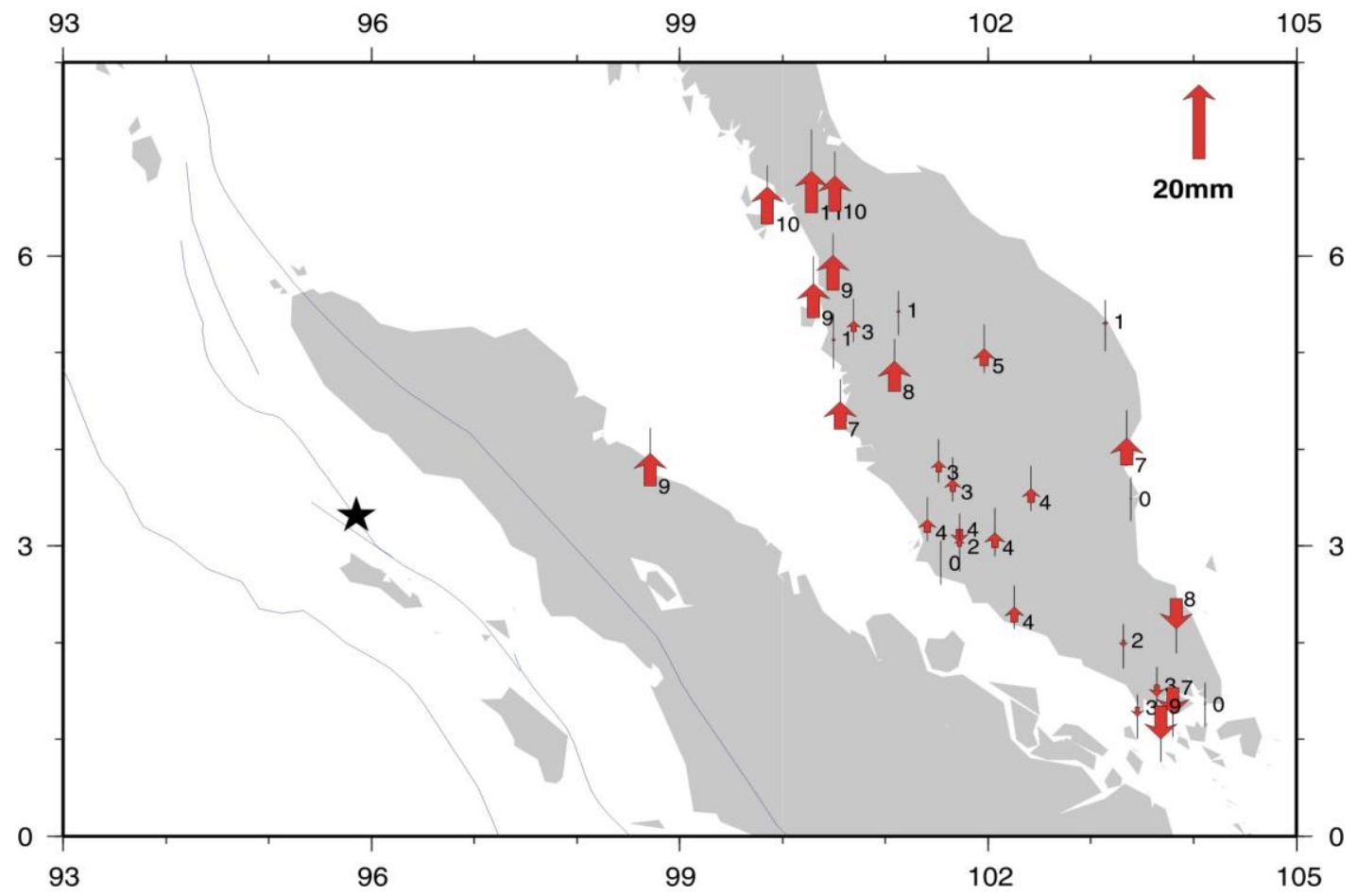

Figure 4. Observed vertical deformation in peninsular due to Aceh earthquake. Red arrows represent vertical land motion obtained from the differences between 2-week average before and after earthquake. The star symbol portrays the location of earthquake epicentre (Kee, 2006).

sea level time series. Fortunately, these data are affected in the same manner. When subtracting tidal solutions of sea level from the altimetry solutions over the same time span, regardless of how long the records are, this lunar node effect cancels out (Trisirisatayawong et al., 2011).

However, additional issues to be discussed are related to the cause of sea level rise. The rate of sea level from tide gauge data may be actual, although it may also be caused by vertical movement of the continent due to active tectonic activities in the region. For instance, Kee (2006) observed an uplift of approximation $1 \mathrm{~cm}$ at the northern peninsular at the Malaysian permanent GPS station at Pulau Langkawi, at Arau and at the Universiti Utara Malaysia, during the Aceh Earthquake on 26 December 2004. This is presented in Figure 4. Therefore, a next level comprehensive study on sea level change will need to be associated with regional geodynamics study, including tide gauges, altimeter and collocated GPS measurements.

\section{ACKNOWLEDGMENTS}

The authors wish to express their gratitude to Mohamad Asrul Mustafar and Jhonny from UTM-GNSS and Geodynamics Research Group for their contribution on this project. The authors also would like to thank TUDelft, NOAA, Altimetrics LLC and the Department of Survey and Mapping Malaysia (DSMM) for providing altimetry and tidal data respectively. Special thanks are due to Universiti Teknologi Malaysia for funding this project under the Research University Grant Scheme. Part of the work has been carried out in frame of the EU funded GEO2TECDI-SONG project.

\section{REFERENCES}

Cecile C, Cazenave A, Provost C (2001). Sea level rise past 40 years determined from satellite and in situ observations. Science, 294(5543): 840-842.

Dumont J, Thibaut P, Zanife O, Soussi B, Benveniste J, Femenias P, Vincent $P$, Picot N (2006). Esa and cnes radar altimeters missions, orbits, instrument, data processing and products. In: Symp. "15 years of Progress in Radar Altimetry", 13-18 March, 2006, Venice, Italy, Vol. ESA SP-614. ESA/ESTEC.

Fu LL, Cazenave A (eds.) (2001). Satellite Altimetry and Earth Sciences: A Handbook of Techniques and Applications. Academic Press. San Diego, California, ISBN 0122695423.

Huang M, Zhai G, Ouyang Y, Lu X, Liu C, Wang R (2008). Integrated data processing for multi-satellite missions and recovery of marine gravity field. Terr. Atmos. Ocean. Sci., 19(1-2): 103-109.

Kee TC (2006). Global Positioning System for Earthquake Induced Deformation in Malaysia. Universiti Teknologi Malaysia. Thesis Master of Science, p. 150. 
Loder JW, Garrett C (1978). The 18.6-year cycle of sea surface temperature in shallow seas due to variations in tidalmixing. J. Geophys. Res., 83: 1967-1970.

Lyard F, Lefevre F, Letellier T, Francis O (2006). Modelling the global ocean tides: Modern insights from FES2004. Ocean Dyn., 56: 394415.

Mitchum G, Cheney R, Fu LL, Provost CL, Menard Y, Woodworth P (2001). The future of sea surface height observations. In: Observing the Ocean for Climate in the 21st Century. Bureau of Meteorology, Australia, pp. 120-136.

Naeije M, Scharroo R, Doornbos E, Schrama E (2008). Global altimetry sea-level service: Glass. NUSP-2 report GO 52320 DEO, NIVR/DEOS.

Nerem RS, Chambers DP, Leuliette EW, Mitchum GT, Cazenave A (2006). Satellite measurements of sea level change: Where have we been and where are we going? In: Symp. "15 years of Progress in Radar Altimetry," 13-18 March 2006, Venice, Italy, Vol. ESA SP-614. ESA/ESTEC.
Nerem RS, Mitchum T (2001). Sea level change. In: L.L. Fu, A. Cazenave (eds.) Satellite Altimetry and Earth Sciences: A Handbook of Techniques and Applications, Academic Press, San Diego, California. pp. 329-349. ISBN 0122695423.

Omar K, Ses S, Naeije M, Mustafar M (2006). The Malaysian seas: Variation of sea level observed by tide gauges and satellite altimetry. Technical memorandum, Universiti Teknologi Malaysia (UTM), Kuala Lumpur, Malaysia, p. 20

Ray R (1999). A global ocean tide model from TOPEX/Poseidon altimetry: GOT99.2. NASA Tech. Memo. 209478, Goddard Space Flight Center, Greenbelt, Maryland, p. 58.

Trisirisatayawong I, Naeije M, Simons W, Fenoglio-Marc L (2011). Sea level change in the Gulf of Thailand from GPS corrected tide gauge data and multi-satellite altimetry. Global Planet. Change, 76: 137151. 


\section{APPENDIX}

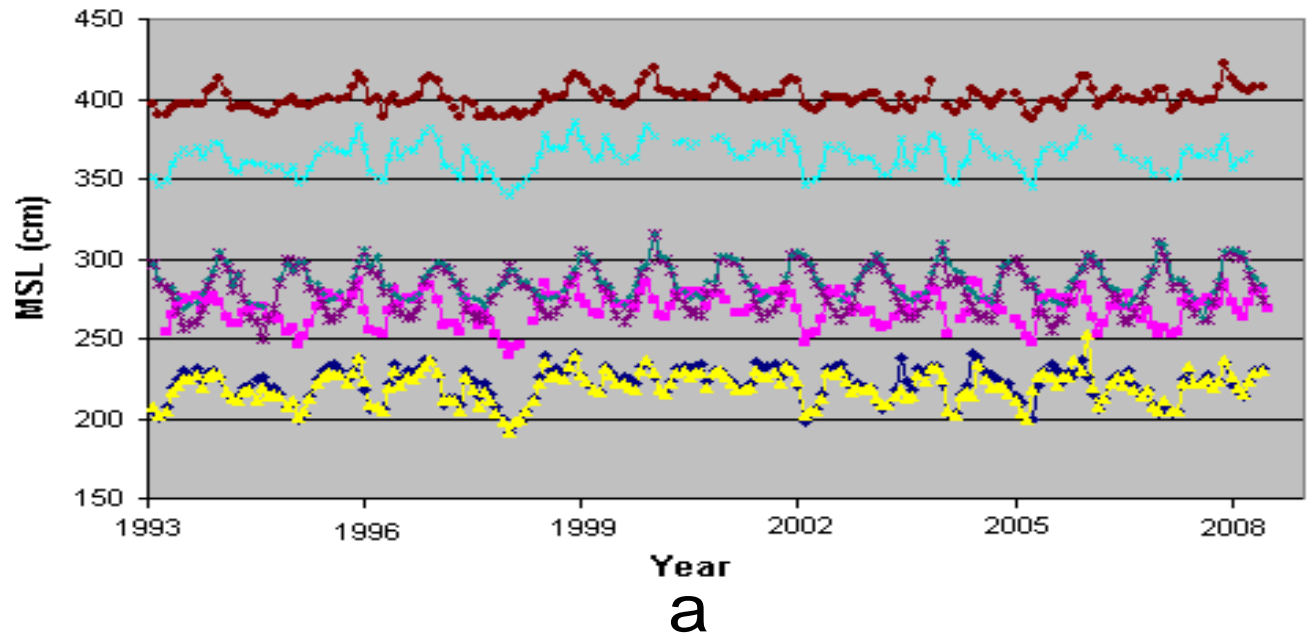

$\longrightarrow$ - P. Langkawi
$=$ P. Pinang
Lumut
$\ldots$ Port Klang
$\rightarrow$ Tg. Keling
$\rightarrow$ Kukup
- Johor Bahru
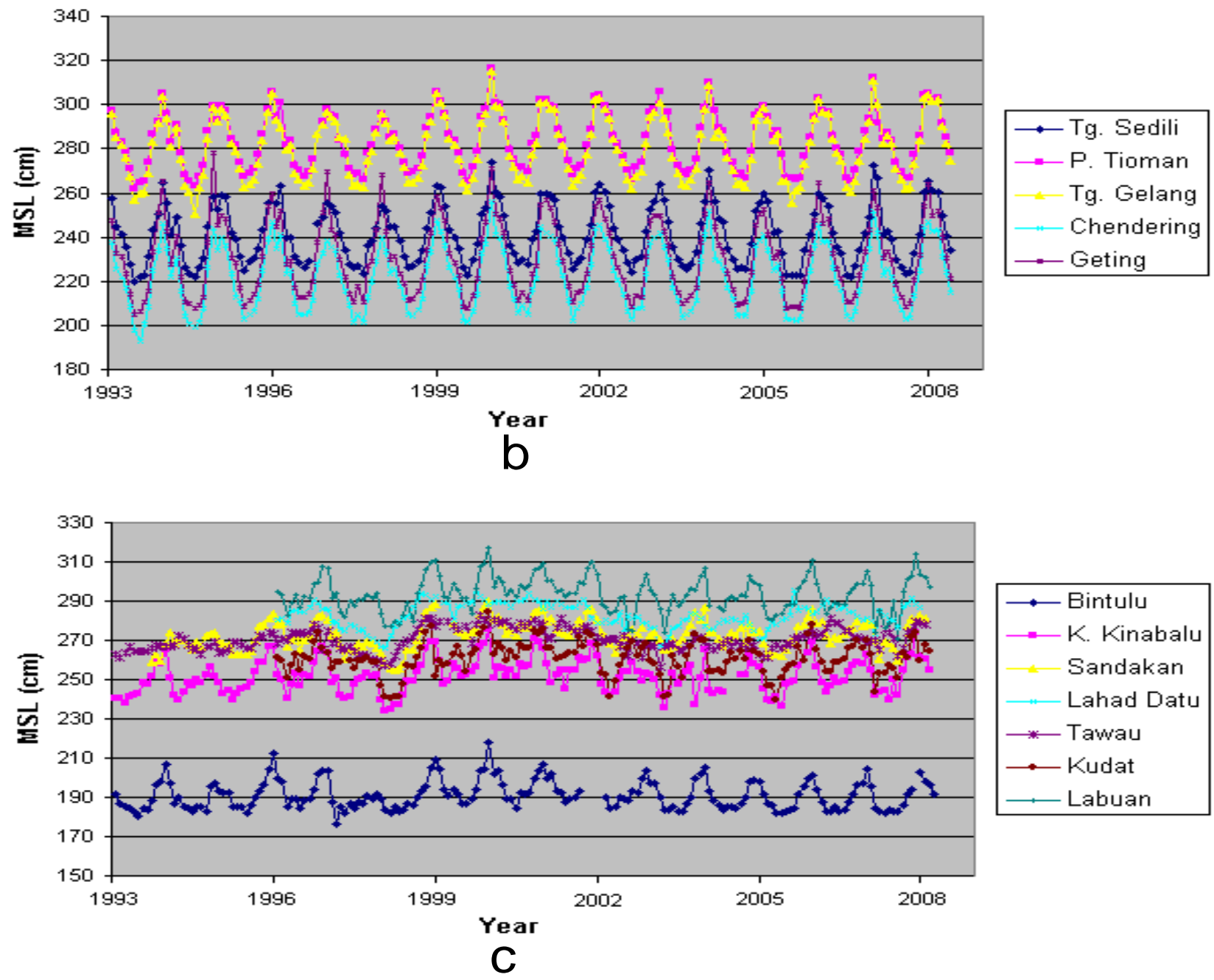

Figure A1. Monthly mean sea level for tide gauge stations near the west of Peninsular Malaysia (a), the east coast of Peninsular Malaysia (b) and near Sabah and Sarawak (c). 


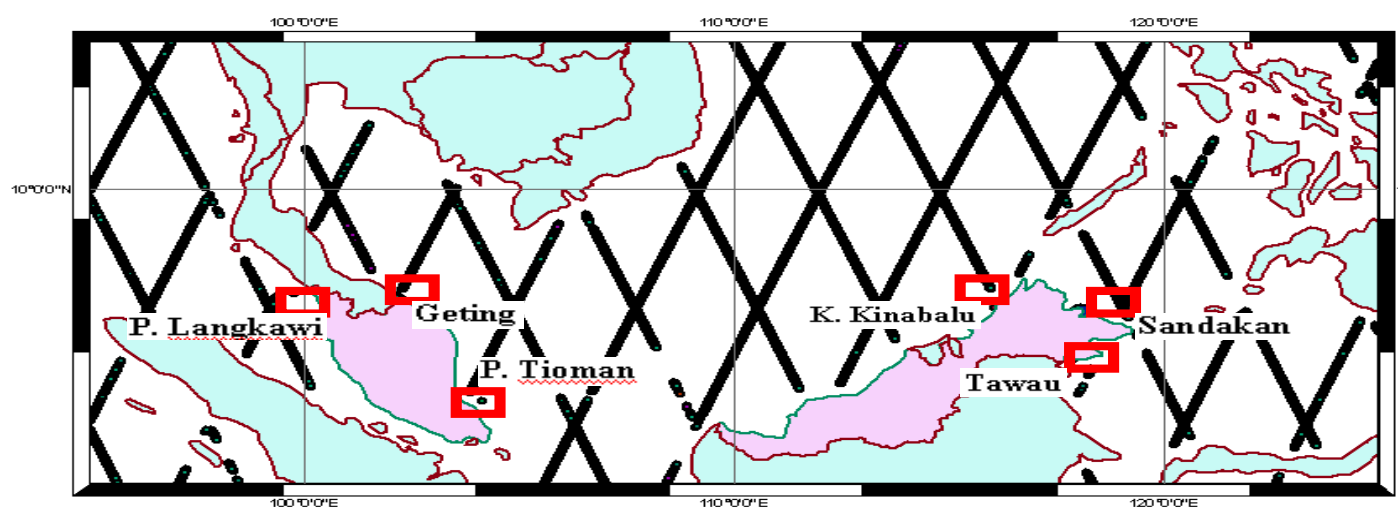

Figure A2. The Selected $1^{\circ} \times 1^{\circ}$ bin areas nearby tide gauge stations.
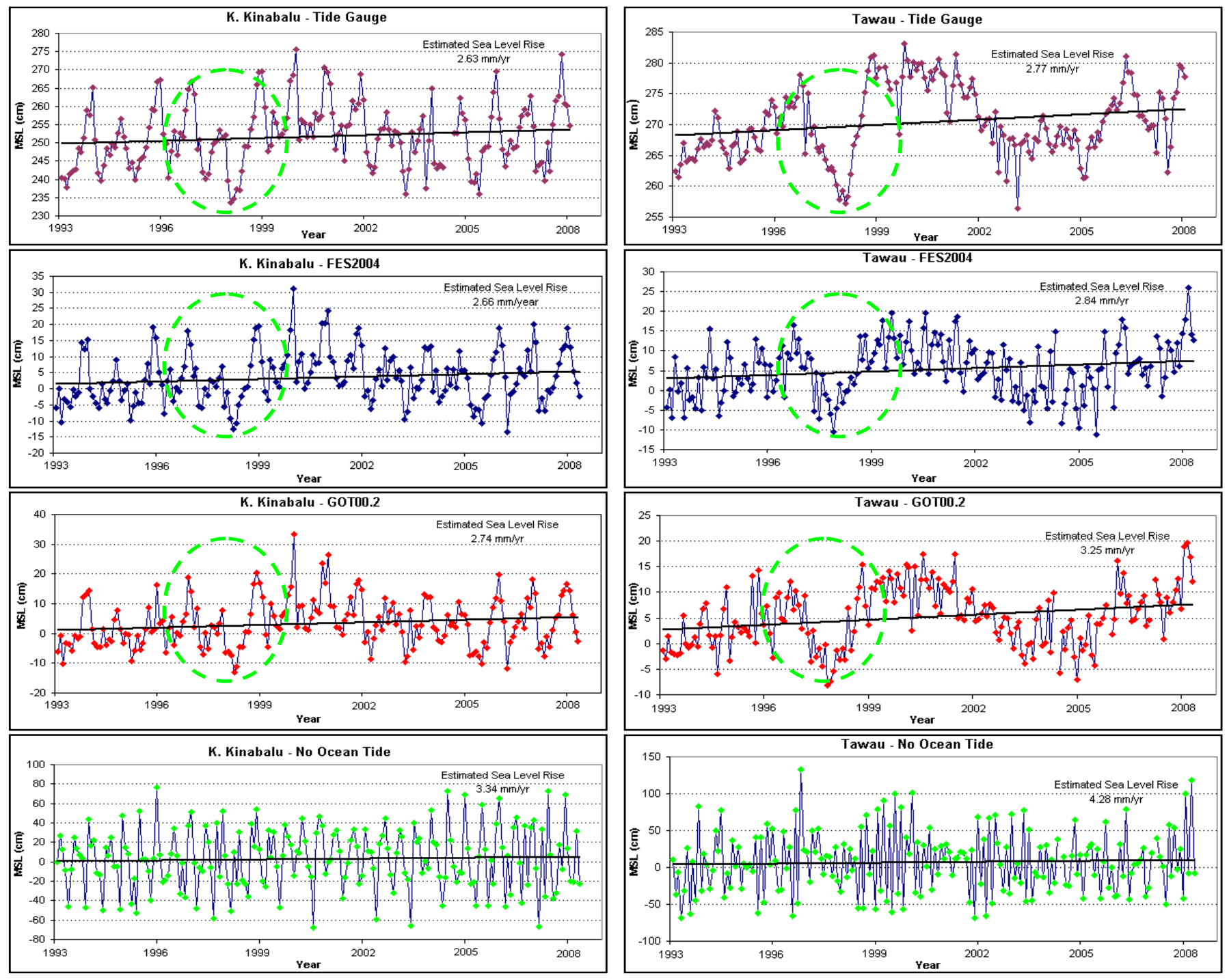

Figure A3. Sea level changes at Kota Kinabalu and Tawau based on tidal and altimeter data. 

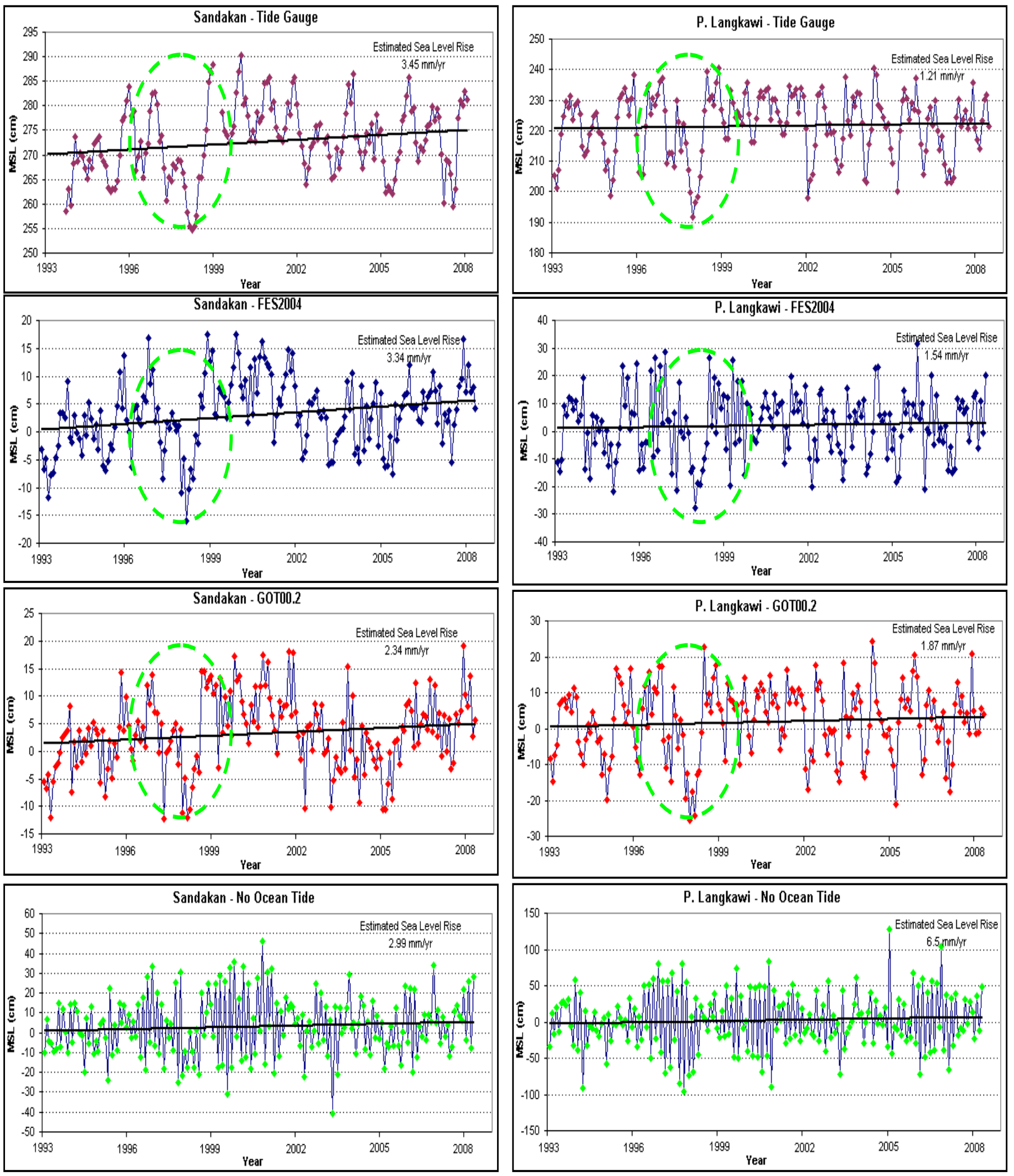

Figure A4. Sea level changes at Sandakan and P. Langkawi based on tidal and altimeter data. 

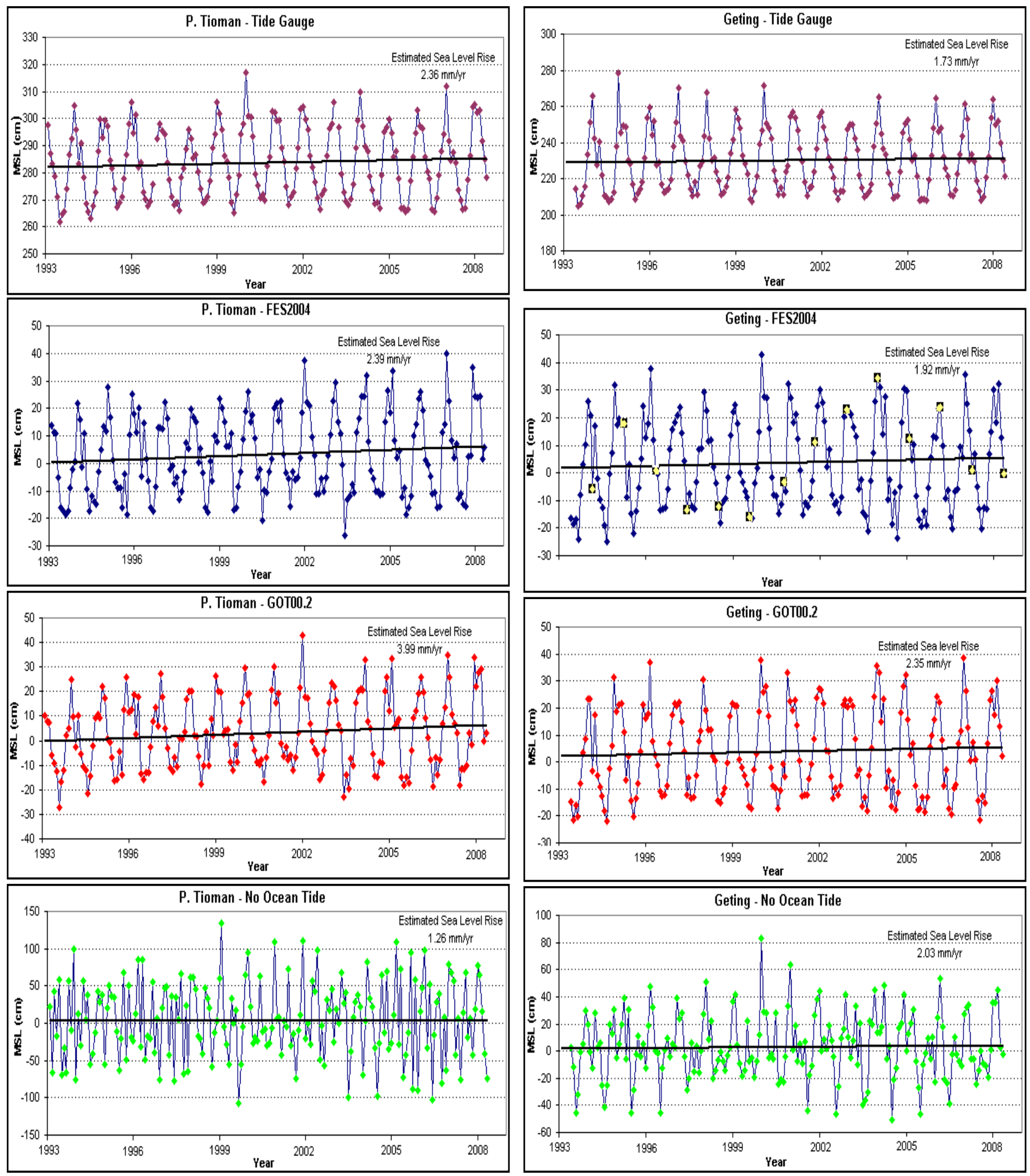

Figure A5. Sea level changes at P. Tioman and Geting based on tidal and altimeter data. 
Table A1. Summary of tide gauge and altimeter results and difference.

\begin{tabular}{lllccc}
\hline Tide model & Location & Period & Tide Gauge $(\mathbf{m m} / \mathbf{y r})$ & Altimeter $(\mathbf{m m} / \mathbf{y r})$ & Difference $(\mathbf{m m} / \mathbf{y r})$ \\
\hline & K. Kinabalu & 1993 to 2008 & 2.63 & 2.66 & 0 \\
& Tawau & 1993 to 2008 & 2.77 & 2.84 & -0.1 \\
& Sandakan & 1993 to 2008 & 3.45 & 3.34 & 0.1 \\
& Geting & 1993 to 2008 & 1.73 & 1.92 & -0.2 \\
& P. Tioman & 1993 to 2008 & 2.36 & 2.39 & 0 \\
& P. Langkawi & 1993 to 2008 & 1.21 & 1.54 & -0.3 \\
\hline & K. Kinabalu & 1993 to 2008 & 2.63 & 2.74 & -0.1 \\
\multirow{5}{*}{ GOT00.2 } & Tawau & 1993 to 2008 & 2.77 & 3.25 & -0.5 \\
& Sandakan & 1993 to 2008 & 3.45 & 2.34 & 1.1 \\
& Geting & 1993 to 2008 & 1.73 & 2.35 & -0.6 \\
& P. Tioman & 1993 to 2008 & 2.36 & 3.99 & -1.6 \\
& P. Langkawi & 1993 to 2008 & 1.21 & 1.87 & -0.7 \\
\hline & K. Kinabalu & 1993 to 2008 & 2.63 & 3.34 & -0.7 \\
& Tawau & 1993 to 2008 & 2.77 & 4.28 & -1.5 \\
No Model & Sandakan & 1993 to 2008 & 3.45 & 2.99 & 0.5 \\
& Geting & 1993 to 2008 & 1.73 & 2.03 & -0.3 \\
& P. Tioman & 1993 to 2008 & 2.36 & 1.26 & 1.1 \\
& P. Langkawi & 1993 to 2008 & 1.21 & 6.50 & -5.3 \\
\hline
\end{tabular}

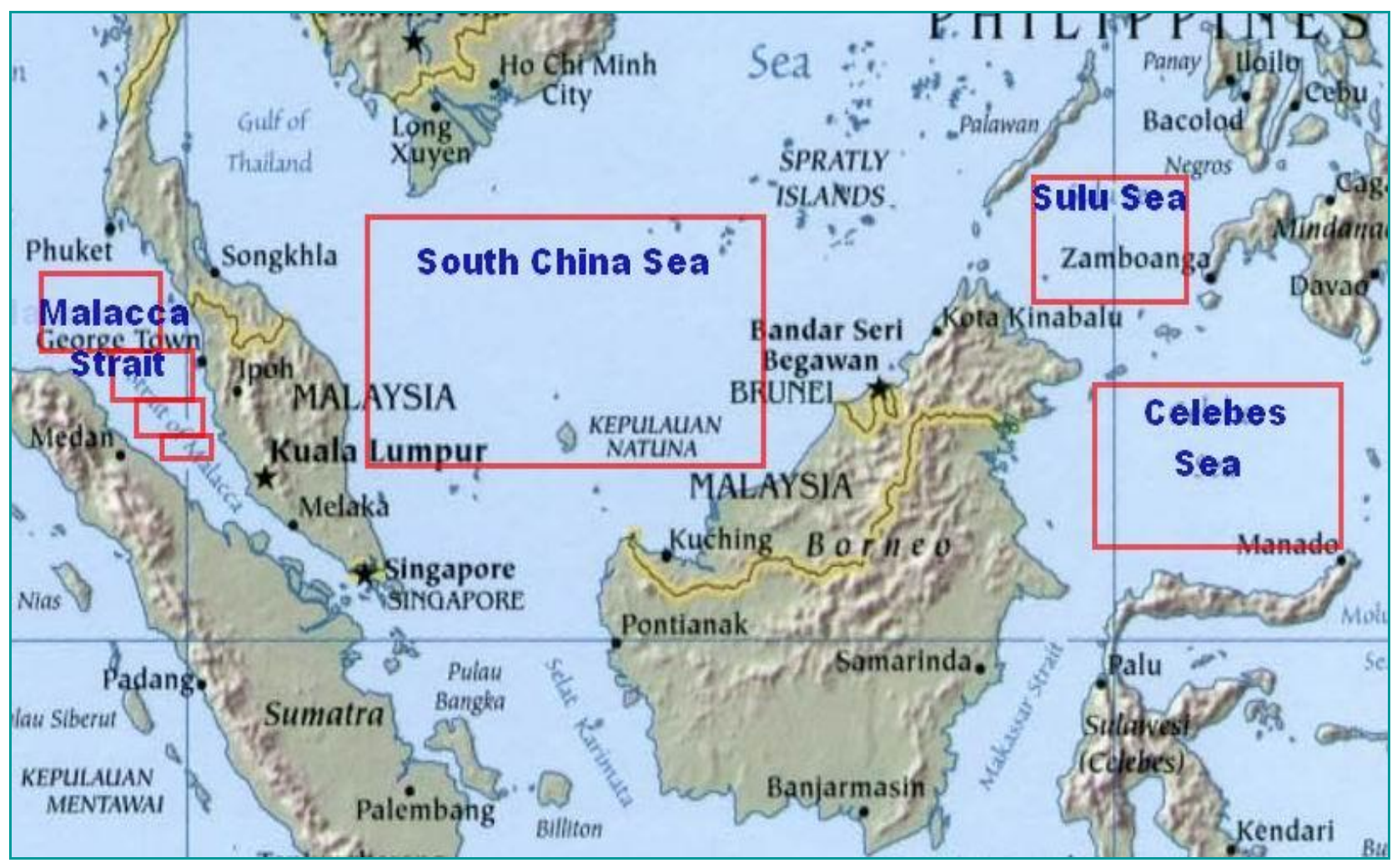

Figure A6. The chosen study areas in Malaysian waters. 


\section{ERS1/ERS2/ENVISAT}

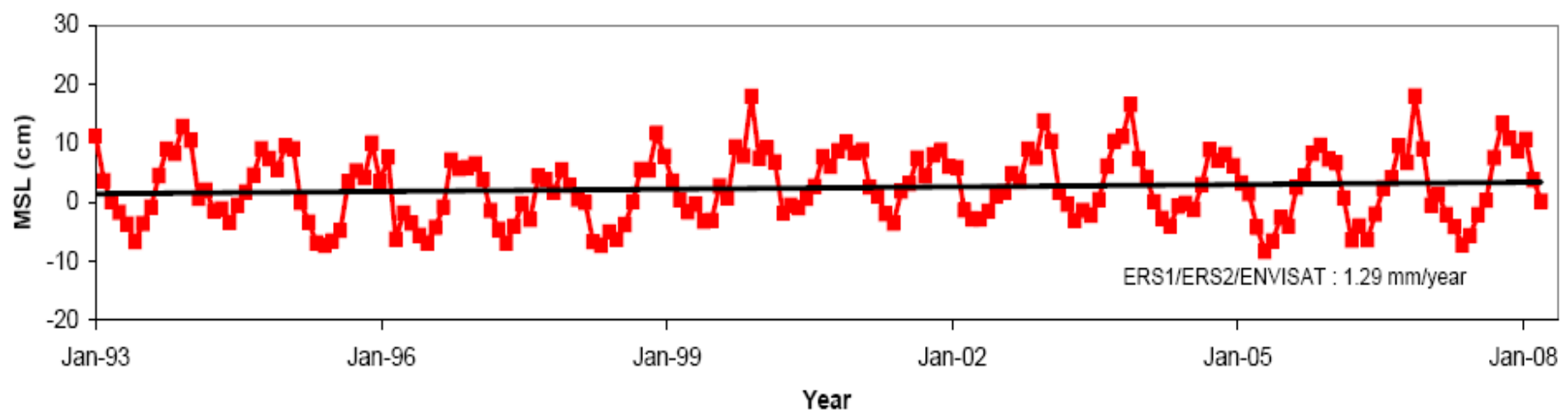

ALL SATELLITE COMBINATION

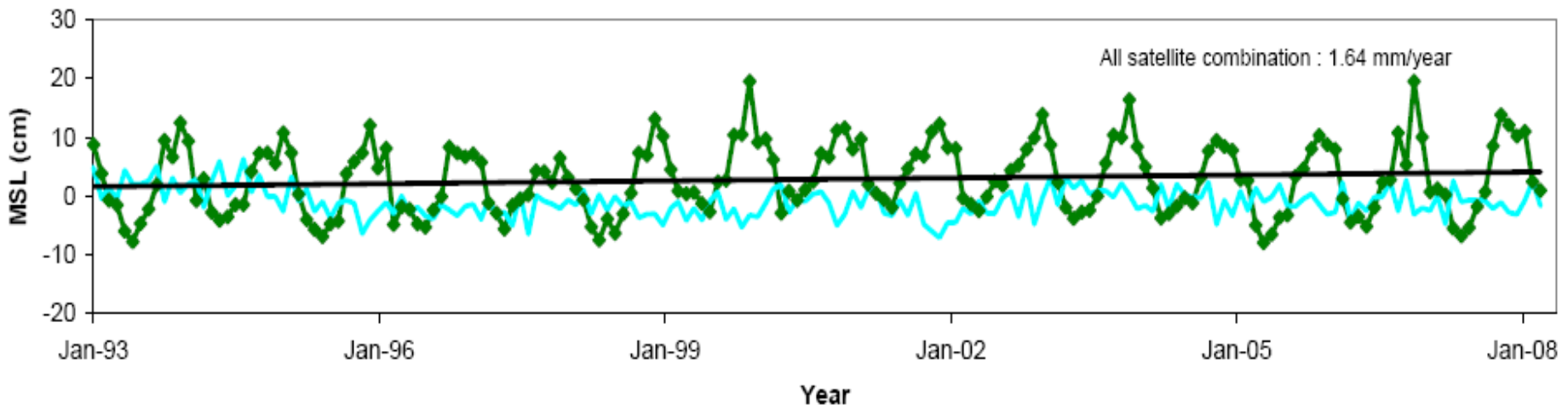

TOPEX/JASON1

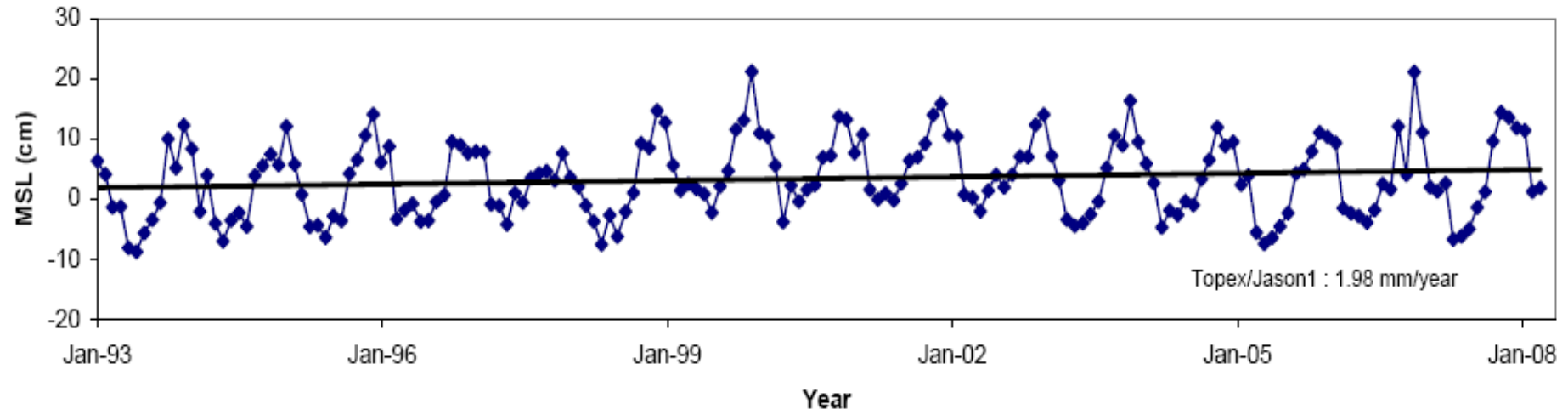

Figure A7. Plot of Sea Level Time Series of South China Sea. Top, combination of TOPEX and Jason-1; centre, combination of ERS-1, ERS-2 and Envisat; bottom, all satellites combination. Light green line refers to the differences of sea level trend between TOPEX/Jason1 and ERS-1/ERS-2/Envisat track. 
TOPEX/JASON1

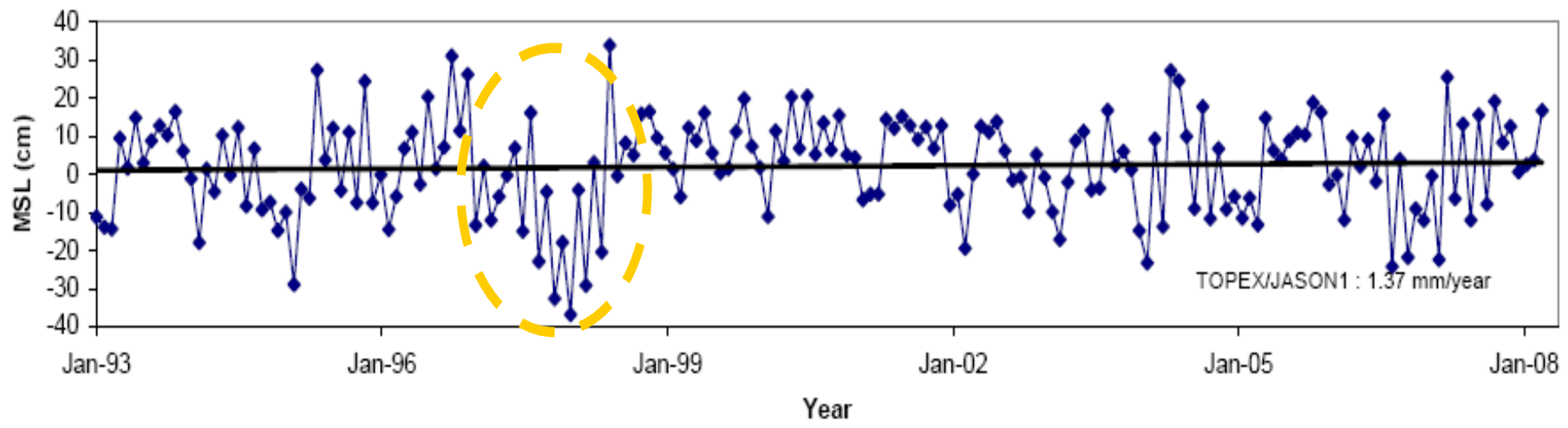

ERS1/ERS2/ENVISAT

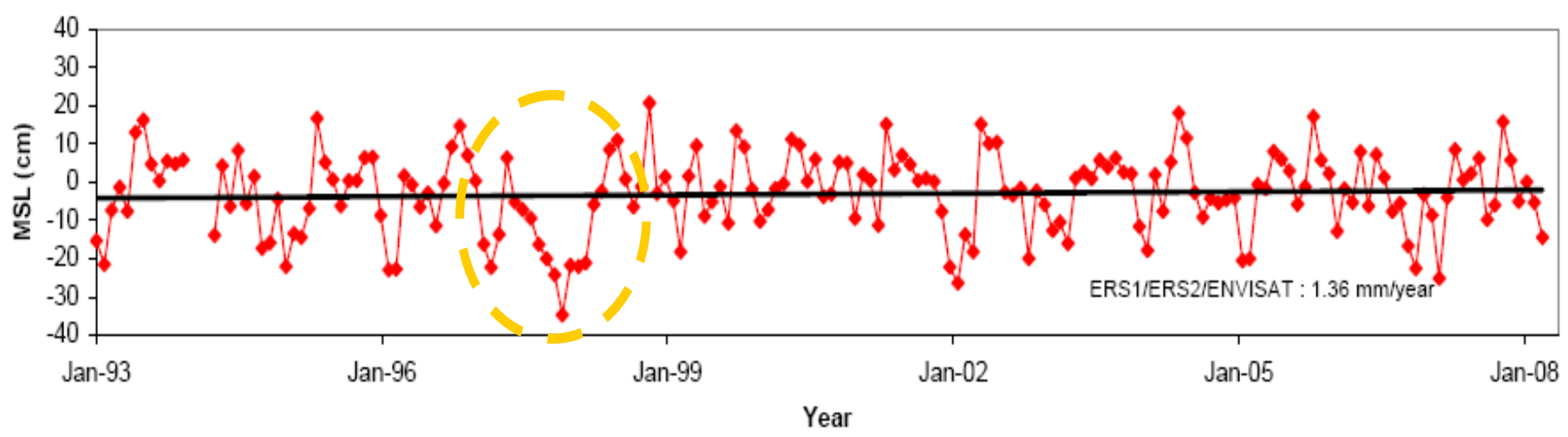

\section{ALL SATELLITE COMBINATION}

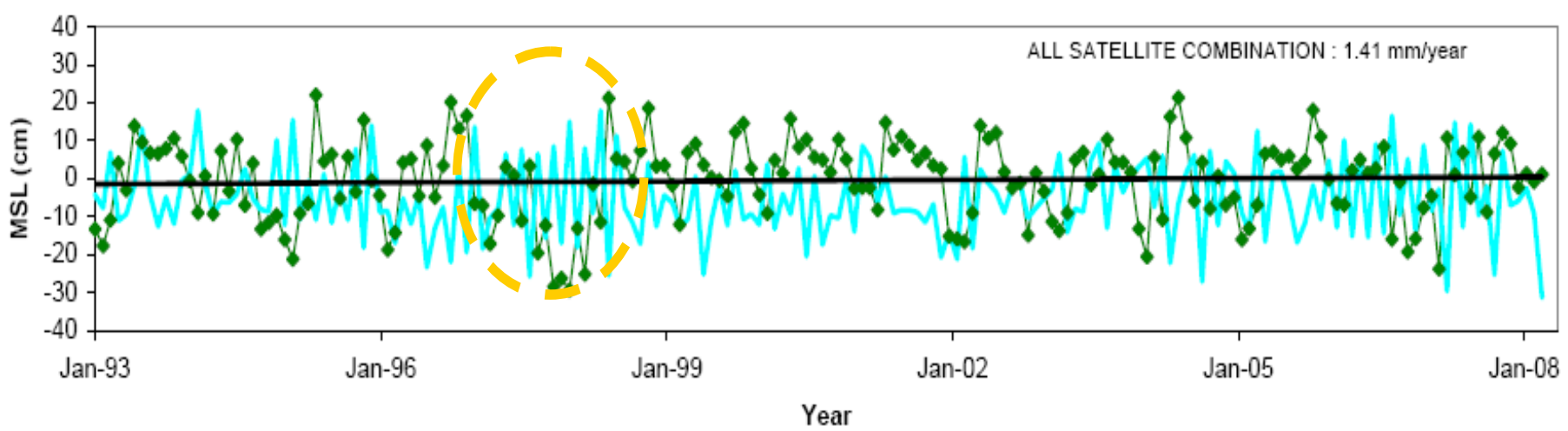

Figure A8. Plot of sea level time series of Malacca Straits. Top, combination of TOPEX and Jason-1; centre, combination of ERS-1, ERS2 and Envisat; bottom, all satellites combination. Light green line refers to the differences of sea level trend between TOPEX/Jason1 and ERS-1/ERS-2/Envisat track. 


\section{TOPEX/JASON1}

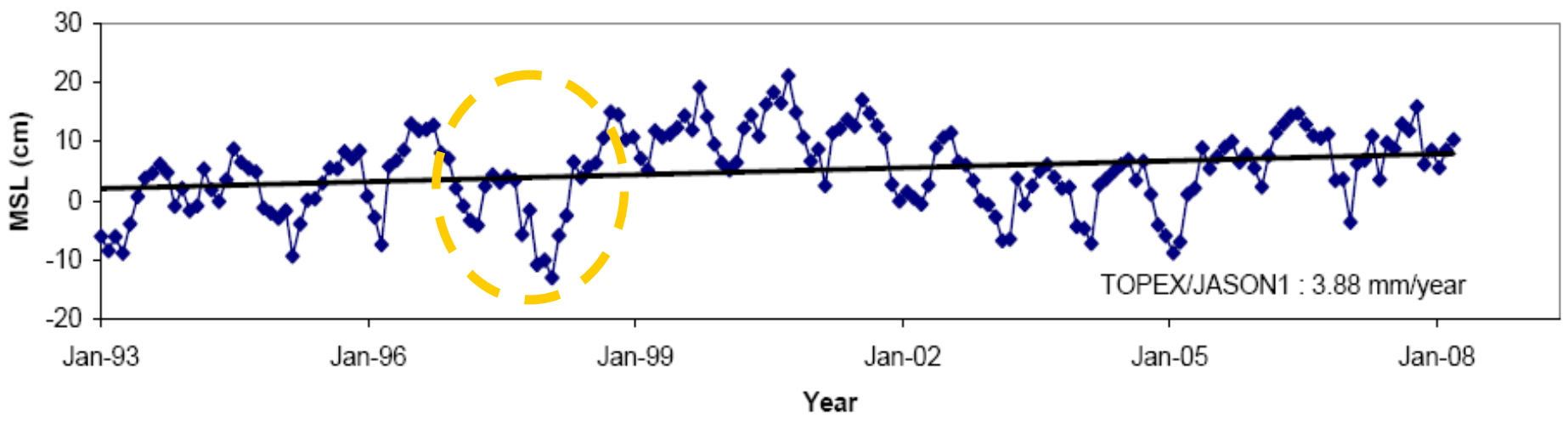

ERS1/ERS2/ENVISAT

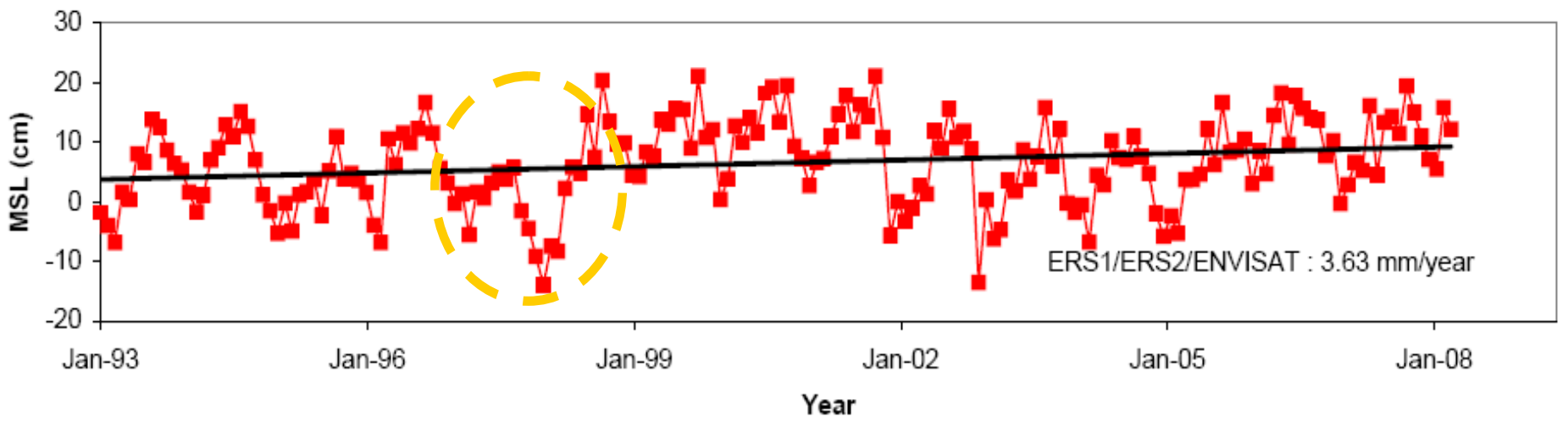

\section{ALL SATELLITE COMBINATION}

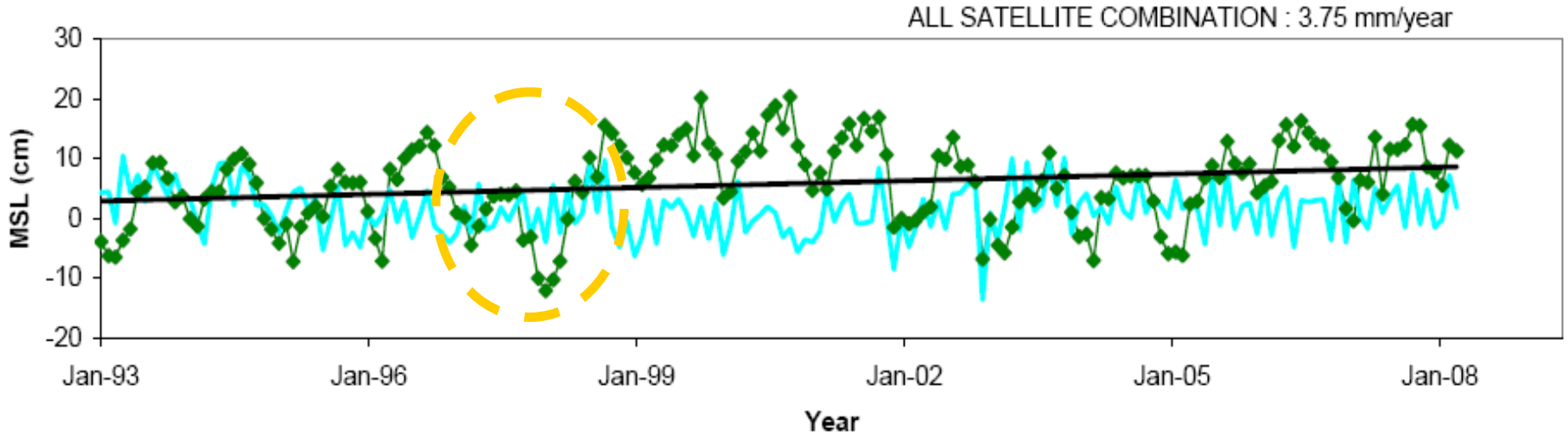

Figure A9. Plot of Sea Level Time Series of Sulu Sea. Top, combination of TOPEX and Jason-1; centre, combination of ERS-1, ERS-2 and Envisat; bottom, all satellites combination. Light green line refers to the differences of sea level trend between TOPEX/Jason1 and ERS1/ERS-2/Envisat track. 
TOPEX/JASON1

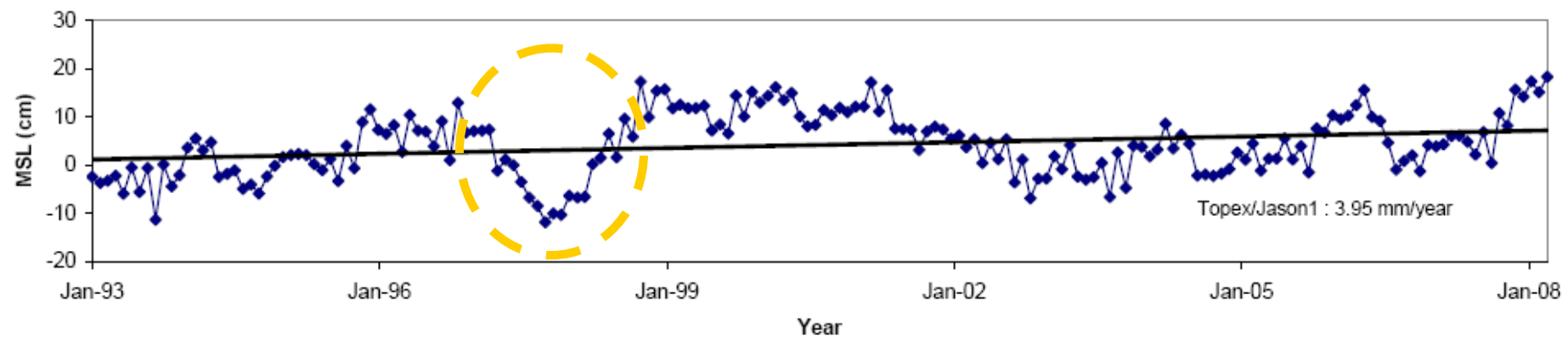

ERS1/ERS2/ENVISAT

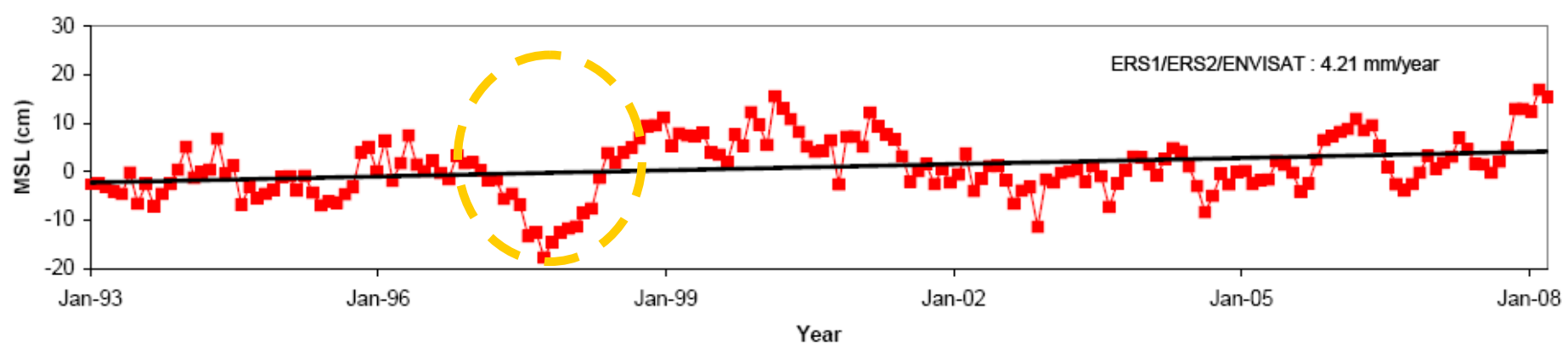

ALL SATELLITE COMBINATION

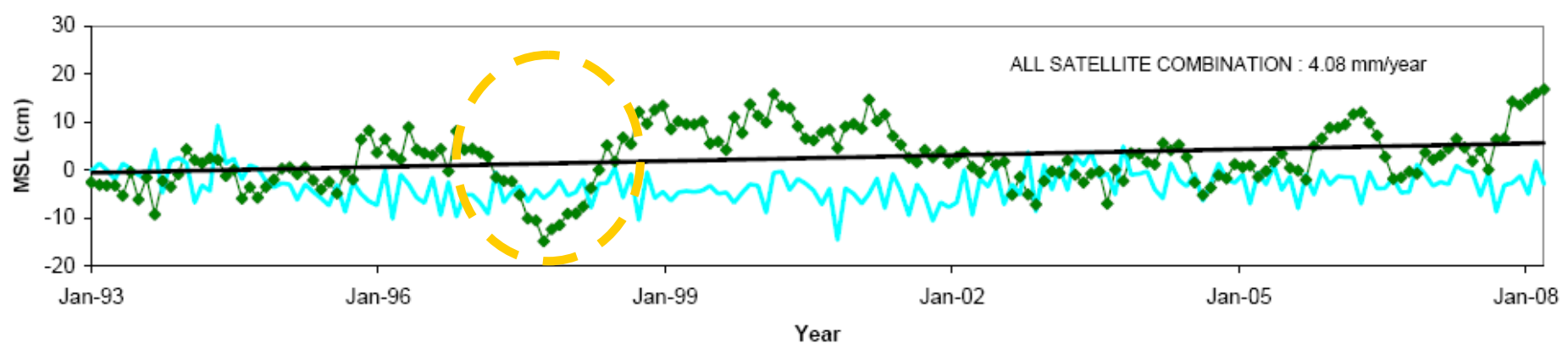

Figure A10. Plot of Sea Level Time Series of Celebes Sea. Top, combination of TOPEX and Jason-1; centre, combination of ERS-1, ERS-2 and Envisat; bottom, all satellites combination. Light green line refers to the differences of sea level trend between TOPEX/Jason1 and ERS1/ERS-2/Envisat track. 